\title{
Toward a unified science of the Earth's surface: Opportunities for synthesis among hydrology, geomorphology, geochemistry, and ecology
}

\author{
Chris Paola, ${ }^{1}$ Efi Foufoula-Georgiou, ${ }^{2}$ William E. Dietrich, ${ }^{3}$ Miki Hondzo, ${ }^{2}$ \\ David Mohrig, ${ }^{4}$ Gary Parker, ${ }^{5}$ Mary E. Power, ${ }^{6}$ Ignacio Rodriguez-Iturbe, ${ }^{7}$ \\ Vaughan Voller, ${ }^{2}$ and Peter Wilcock ${ }^{8}$
}

Received 13 June 2005; revised 4 November 2005; accepted 14 November 2005; published 30 March 2006.

[1] The Earth's surface is shaped by the interaction of tectonics, water, sediment, solutes, and biota over a wide range of spatial and temporal scales and across diverse environments. Development of a predictive science of Earth surface dynamics integrates many disciplines and approaches, including hydrology, geomorphology, ocean and atmospheric science, sedimentary and structural geology, geochemistry, and ecology. This paper discusses challenges, opportunities, and a few example problems that can serve as pathways toward this integration.

Citation: Paola, C., E. Foufoula-Georgiou, W. E. Dietrich, M. Hondzo, D. Mohrig, G. Parker, M. E. Power, I. Rodriguez-Iturbe, V. Voller, and P. Wilcock (2006), Toward a unified science of the Earth's surface: Opportunities for synthesis among hydrology, geomorphology, geochemistry, and ecology, Water Resour. Res., 42, W03S10, doi:10.1029/2005WR004336.

\section{Earth Surface Dynamics as an Integrator}

[2] Understanding the dynamics of the Earth's surface, from tectonic processes to microbial weathering, is one of the great integrating challenges of modern science. The emerging field of "morphodynamics," the study of the properties and evolution of surface morphology, is at the center of this challenge. Because the Earth's surface spans an enormous range of environments, spatial scales, and timescales, a fully realized science of Earth surface dynamics serves as a natural integrator of many disciplines and approaches, including hydrology, geomorphology, ocean and atmospheric science, geology and ecology. Unfortunately, the level of interaction among these fields to date has been nowhere near adequate to the task.

[3] This short paper is a call for the scientific community to work together toward this grand goal: developing a unified surface process science that would integrate insight from all of the above fields to provide a comprehensive and predictive understanding of the dynamics of our planet's surface. Integrated Earth surface dynamics is at the core of

\footnotetext{
${ }^{1}$ Department of Geology and Geophysics and St. Anthony Falls Laboratory, University of Minnesota Twin Cities, Minneapolis, Minnesota, USA.

${ }^{2}$ Department of Civil Engineering and St. Anthony Falls Laboratory, University of Minnesota Twin Cities, Minneapolis, Minnesota, USA.

${ }^{3}$ Department of Earth and Planetary Science, University of California, Berkeley, California, USA.

${ }^{4}$ Department of Earth, Atmospheric, and Planetary Science, Massachusetts Institute of Technology, Cambridge, Massachusetts, USA.

${ }^{5}$ Department of Civil Engineering, University of Illinois, Urbana, Illinois, USA.

${ }^{6}$ Department of Integrative Biology, University of California, Berkeley, California, USA.

${ }^{7}$ Department of Civil and Environmental Engineering, Princeton University, Princeton, New Jersey, USA.

${ }^{8}$ Department of Geography and Environmental Engineering, Johns Hopkins University, Baltimore, Maryland, USA.
}

Copyright 2006 by the American Geophysical Union. 0043-1397/06/2005WR004336 environmental science; after all, the Earth's surface is "the environment" for most life and human activity. Hydrology is clearly central to the effort, and not only because of the role of terrestrial surface and groundwater in creating surface morphology. A quantitative style is deeply ingrained in hydrology, hence it has much to offer in accelerating the infusion into Earth surface dynamics of quantitative methods for dealing with complex natural systems.

[4] In this paper we focus on channels and channel networks as a starting point in the development of a unified approach to surface process science. Most of the continental surface is drained by channels, which can be seen as the arterial system of the landscape, which control, to a large extent, the spatial and temporal patterns of physical, chemical, and biotic processes. Channel networks illustrate a fascinating aspect of morphodynamics: the occurrence of similar patterns across a wide range of environments and scales. Tributary networks are the most prominent example but the list of recurring structures includes distributary networks; braided networks; bed forms; channel bends, bars, and scour pits; splays and lobes; and clinoforms (e.g., deltas, continental margins). These spatial patterns are not restricted to the terrestrial landscape but, with remarkable similarity of form, structure submarine landscapes as well.

[5] The similarity of channel networks across environments and scales has been known for some time, but the last 20 years have seen a revolution in the range and power of quantitative tools to explore and measure spatial structure and similarity [Rodriguez-Iturbe and Rinaldo, 1997]. This has been accompanied by a dramatic increase in the quality and quantity of topographic data on which to apply them, and by major advances in the theory of fundamental channel structures [Federici and Seminara, 2003; Parker and Izumi, 2000; Seminara and Tubino, 1989, 2001; Sun et al., 1996; Sun and Parker, 2005]. The importance of these recurring, self-formed patterns is not restricted to the physical landscape. By structuring the landscape and localizing the flow of water, sediment, and nutrients, channels and channel 
networks play a major role in controlling spatial patterns and dynamics of biota and geochemical processes. The combination of ubiquity, similarity, and strong control on topography and material fluxes makes channel networks and related spatial forms a natural organizing template for environmental observation, modeling, and prediction. Channels and channel networks provide a common spatial framework for interpreting a broad range of local environmental observations, for transferring results from one system and scale to another (including from laboratory to nature), and, by understanding how the channel structure mediates organization in local physical, ecological, and geochemical variables (e.g., vegetation and fluxes of sediment and nutrients), for environmental modeling and prediction.

[6] Channel networks have been traditionally seen by hydrologists as relatively static boundary conditions. Water is routed through them to predict the hydrologic response of a basin to a given precipitation input. Less emphasis has been placed on the evolution of the channel geometry and the coevolution of the channel and its floodplain, which determine nutrient and sediment delivery downstream as well as the variability of extreme floods, which are influenced by overbank storage and release of water. In terms of physical processes, we can divide the surface realm into three broad timescales, corresponding to shortest scale on which important variability occurs: a "water" timescale of minutes to hours; a "sediment" timescale of hours to centuries, and a "tectonic" timescale of centuries and up. The static view of channel systems breaks down as we move from the "water" to the "sediment" scale because the channel geometry is essentially controlled by the sediment flux, including storage, at a given time. Thus the connection between hydrology and surface dynamics must strengthen as hydrologists tackle longer-term forecasting problems, or problems where changes in land use or climate could lead to major changes in sediment yield and hence channel properties and conveyance.

\section{Motivation for Integrated Earth Surface Science: Three Examples}

[7] There are many ways in which a unified approach to Earth surface dynamics would benefit science and society. Major application areas include environmental forecasting, river and landscape restoration and management, assessing location, size, and geometry of subsurface fluid conduits and reservoirs, hazard assessment and reduction, and quantifying cycling and storage of carbon and other major geochemical actors. Here we provide three examples that illustrate the need for combined research in hydrology, ecology, geochemistry, and geomorphology:

\subsection{Generalized Environmental Forecasting: Beyond Climate}

[8] It is now becoming possible to forecast the effect of, for instance, a doubling of atmospheric carbon dioxide level on rainfall and temperature in a given area [Bonan et al., 2002; Stainforth et al., 2005; Intergovernmental Panel on Climate Change, 2001]. How would such climatic changes affect streamflow and the spatial and temporal patterns of sediment and solute flux through the channel network? This question is difficult to answer for a static channel network and all the more difficult when dynamic interactions between network fluxes and geometry are considered. Chang- ing rainfall, for example, would directly affect rates of sediment and solute creation and delivery to streams in ways that cannot at present be predicted with confidence. Sediment flux and caliber strongly influence channel dimensions and so would be expected to affect flood statistics and habitat. In addition, the rainfall changes could also change the distribution of biota from microbes to trees and burrowing animals on hillslopes and floodplains. These organisms are directly involved in mediating sediment production and delivery, so changes in the ecosystem could significantly affect sediment flow as well as channel morphology (through, for instance, bank stabilization). The point is that at present, considering the whole physicalbiological-chemical system of a watershed, we cannot predict even qualitatively how it will respond to climate and land use changes.

\subsection{Stream Restoration}

[9] An increasing public interest in the environmental, recreational, and esthetic values of rivers has led to increased recognition of the impact of human actions and the desire to return rivers to a more natural, attractive, and resilient state. This has created a substantial demand for restoration or rehabilitation of impaired streams, creating a booming but mostly small-scale industry known generically as "stream restoration" [Wohl et al., 2005]. Projects in the United States alone number in the tens of thousands, with associated costs measured in billions of dollars per year [Bernhardt et al., 2005]. Restoration efforts range from local projects on short reaches of small streams to multibillion dollar projects such as restoration of the Everglades and the Mississippi Delta.

[10] The scientific basis for stream restoration is weak, the success of existing projects not well known, and the connection between research and practice is poorly developed. Current stream restoration practice is based on analogy; a template is sought in a nearby or idealized channel that the designer judges to be suitable. However, if a disturbed stream is adjusting to changes in essential controlling factors, a template for analog-based design is unlikely to exist [Wilcock, 1997]. What is needed instead is a testable, predictive framework linking cause and effect. Such a framework must be based on a quantitative, transdisciplinary understanding of the physical, chemical, and biological dimensions of disturbance and recovery in streams, accounting for natural and human-induced variability.

[11] A major challenge facing a predictive restoration science is placing the restoration project in a watershed context. The most obvious and persistent cause of physical failure is ignoring, or inadequately predicting, the supply of water and sediment from the watershed. Current best practice is generally based on a narrative watershed history identifying the timing and location of major watershed disturbances, including anthropogenic changes. Predictive restoration science requires transforming this history to a quantitative basis and integrating historical records with landscape-scale predictive modeling.

\subsection{Surface to Subsurface}

[12] The interaction of surface water and groundwater is a major research issue in hydrology. An analogous problem in surface dynamics is the relation between surface dynamics in active depositional systems and subsurface stratigraphy. 
Depositional subsurface architecture in turn controls the spatial heterogeneity of permeability and porosity, and hence the flow of subsurface fluids like water and hydrocarbons. Major challenges include: understanding surface dynamics in depositional systems, including biotic influences; understanding how surface processes interact with external drivers like sea level, sediment supply, climate, and subsidence; and understanding how surface dynamics in time and space is transformed into three-dimensional subsurface structure. Modern high-resolution seismic imaging methods [Davies and Posamentier, 2005] provide subsurface data analogous to LIDAR topography data, except that the subsurface data are three-dimensional and provide a record of temporal evolution. Learning to exploit these records will transform sedimentary geology, and what it can tell us about both surface dynamics and subsurface structure, just as high-resolution topographic data have transformed geomorphology. The data are costly to obtain and are mostly privately held, so building new partnerships between academia and industry will be critical to advancing this field. However, the effort will be worthwhile: in addition to improved prediction of subsurface heterogeneity, quantitatively coupling surface to subsurface can help provide long-term flux records needed for sustainable restoration and landscape management.

\section{Four Problems for Integrative Research}

[13] Next we pose four problems in integrated Earth surface science that lie at the interface of hydrology, geomorphology, geochemistry, and ecology. These problems, structured around channel networks, represent opportunities for major advances during the coming decade: (1) understanding channel networks across environments and scales to learn from similarities and dissimilarities, (2) relating channel morphology and network geometry to the spatial organization and scaling of floods, sediment fluxes, riparian vegetation, and river food webs, (3) developing new mathematical techniques for modeling and prediction, and (4) exploring the role of new observational techniques and laboratory studies in advancing surface process research.

\subsection{Channel Networks Across Environments and Scales: Tributary Networks, Deltas, Braided Rivers, and Submarine Channels}

[14] Channels organize themselves into networks of various forms that recur across many environments and frequently show self-similarity. Some central questions are: How does the overall (macroscale) pattern arise from smallscale local interactions? What can be learned from the similarities and dissimilarities of those patterns across diverse environments e.g., subaerial and submarine, depositional and erosional? Can organizational principles of channels and channel networks be unified and their physical causes understood for the purposes of improved modeling and prediction? Considerable progress has been made over the years in regard to the scaling signatures of river basins in the upper portion of the river system where most of the water and sediment are produced [Rodriguez-Iturbe and Rinaldo, 1997]. The progress made in understanding the network structure in the erosional uplands stands in contrast with the fact that we are just beginning to understand the distributary structure that characterizes depositional deltas and fans [Syvitski, 2005; Sun et al., 2002]. Yet deltas and fans, though globally much smaller in area, are critical sediment sinks and so determine rates and patterns of delivery of sediment, organic matter, nutrients, and pollutants to the sea. They are also storehouses of hydrocarbons, home to a sizable fraction of the world's population, and as recent events make abundantly clear, a crucial buffer between ocean storms and urban and industrial centers.

[15] Another type of channel organization is that of braided channel systems [Sambrook Smith et al., 2006]; these in effect have a topology intermediate between tributary (junction dominated) and distributary (division dominated) such that both junction types occur about equally often. These are highly complex dynamic systems characterized by intensive but spatially localized erosion, sediment transport and deposition and frequent channel shifting. They have been found to exhibit a statistical scale invariance in their morphology and dynamics which is of similar form in diverse flow regimes, slopes, types of bed material and braid plain widths, indicating the presence of universal features in the underlying mechanisms responsible for the formation of their spatial structure [Foufoula-Georgiou and Sapozhnikov, 2001; Murray and Paola, 1994; Sapozhnikov and Foufoula-Georgiou, 1997] We still need to improve our understanding of the hydraulic geometry of braid channels (e.g., depth-width relationships, velocities at junctions, speed of lateral channel shifts), how these channels interact with vegetation [Bennett and Simon, 2004], and how they dictate the spatial distribution and storage of hydrocarbons and other substances in the subsurface [Lunt et al., 2004a, 2004b].

[16] The submarine landscape is veined with channel systems that appear to be analogous in many ways to their subaerial equivalents. Analogous morphologies include tributary systems [Mitchell, 2004], lobes, bed forms, and meandering channels [Abreu et al., 2003; Das et al., 2004; Imran et al., 1999]. Submarine channel systems are formed largely by turbidity currents: density underflows driven by the weight of suspended sediment. At present, work on developing the analogy between subaerial and submarine channel systems is in a period of rapid growth, fueled in large part by intense interest in deep-water hydrocarbon reservoirs. Since each realm (subaerial, submarine) amplifies certain aspects of the fundamental channel dynamics relative to the other, we gain a clearer picture of channel dynamics by studying them together.

\subsection{Effect of Network Topology and Channel- Floodplain Morphology on the Scaling of Floods, Sediment and Nutrient Fluxes, and Ecosystem Dynamics}

[17] Scaling of floods has been the subject of considerable research in hydrology starting with the simple normalization methods, e.g., the index flood method, to the recent statistical multiscaling theories [Gupta et al., 1994]. A key question concerns the variation of flood intensity and frequency with the drainage area of the basin (scale). Analysis of observations from several regions has supported the inference that floods exhibit a multiscaling structure (i.e., the statistical moments scale as power laws with drainage area with an exponent that depends nonlinearly on the order of the moment) with a scaling break at a characteristic scale. Although such an approach yields a concise statistical model which can be useful for regional 
flood quantile estimation of design events, a number of open questions remain: For example, what is the physical origin of the observed scaling and what determines the scale of the break? What is the relative role of space-time precipitation variability versus geomorphologic controls, e.g., systematic variability of hydraulic geometry with scale and dynamic channel-floodplain interactions, in determining the scaling of floods and streamflow hydrographs [Dodov and Foufoula-Georgiou, 2004, 2005; Menadbe and Sivapalan, 2001]? Bringing sediment into the picture, what controls the size distribution of sediments produced and delivered to channel networks by hillslopes? How are the size distribution and flux rates of bed material affected by the drainage network struture? And how does bedload sediment flux relative to available discharge drive the dynamic evolution of the drainage network structure itself?

[18] Recent research has shed new light on how the spatial structure of ecosystems interacts with the spatial structure of the landscape [Caylor et al., 2004, 2005; Porporato et al., 2004; Porporato and Rodriguez-Iturbe, 2002]. Channel networks provide an organizing template for the ecohydrological and biogeochemical interactions that determine the vegetation patterns and ecosystem dynamics in a river basin. Important questions remain to be answered: What are the feedbacks between flow regime and dynamics of riparian vegetation? What is the relative role of large-scale determinants of vegetation patterns, e.g., optimal response to water stress, and smaller-scale controls mediated by the network structure? What is the relative role of spacetime rainfall variability versus channel network topology in determining the spatial patterns and dynamics of vegetation? How does the physical structure of the landscape influence habitat quality and diversity, and how does it control sources and flows of organisms and limiting nutrients [Power et al., 1995, 2005]? In turn, how do organisms shape the landscape through microbial weathering, the stirring and diffusion of soil, flow baffling and the stabilization of bars, banks and floodplains [Dietrich and Perron, 2006]? What are the coupled dynamics of hillslopefloodplain-stream interactions and what is their role in biogeochemical cycling [Green et al., 2006]?

\subsection{Modeling Tools: Coping With Self-Organization and Variability Across Scales}

\subsubsection{Hierarchical Modeling, Upscaling, or Direct Simulation?}

[19] Channel networks span a wide range of length and timescales. Identifying the scales at which each of these processes operate, i.e., the scales at which they exhibit most of their variability and the major interactions will determine what classes of numerical models would be most pertinent for modeling and prediction. Important questions to be explored include: (1) Can the concepts of homogenization and upgridding, widely used in porous media flows, be adapted for land surface process modeling? (2) Can the concept of large-eddy simulation (LES), widely used in the atmospheric sciences, be adapted to earth surface process sciences to enhance the range of spatial scales over which prediction of earth surface processes can be made? (3) How can we apply often nonlinear slope-dependent flux laws [Dietrich et al., 2003] to fractal landscape surfaces? (4) Is direct simulation, i.e., mechanistic modeling based on small-scale processes, computationally feasible and conceptually valid in light of the complexity of earth surface systems and the spontaneous emergence of organization at larger scales [Werner, 1999]?

\subsubsection{Data Assimilation and Ensemble Prediction in Earth Surface Dynamics}

[20] Data assimilation and probabilistic prediction are now recognized to be essential elements of any numerical modeling system of complex natural phenomena. The goal of data assimilation is to produce a regular, physically consistent representation of a system from a heterogeneous collection of in situ and remote sensing observations that sample the system imperfectly and irregularly in space and time. Can naturally occurring similar spatial structure such as that provided by channel networks be used to improve both positioning of local environmental sensors and assimilation and interpolation of locally sensed data?

[21] Probabilistic prediction acknowledges that there is uncertainty in our understanding of the physical system and therefore in the equations and/or parameters that we use to describe it as well as in the initial conditions of the system. Therefore a single deterministic prediction of a future state of the system is not adequate and a suite of such predictions (ensemble prediction) which account for all uncertainties is needed. The areas of data assimilation and ensemble prediction have been extensively explored in the oceanic and atmospheric sciences and more recently in the hydrologic sciences. How can these methods be best adapted to Earth surface science?

\subsubsection{Coupling Across Scales, Nonlinear Dynamics, and Predictability}

[22] Channel systems, and landscapes in general, are formed by nonlinear processes that interact with each other over a wide range of scales. Prediction of a future state of the system knowing its initial conditions is a fundamental problem with important applications in geomorphologic restoration and planning. It is known that in many natural systems, small perturbations can lead to larger-scale disturbances (even under constant forcing) altering the evolution of the system and reducing its predictability from an initial known state. Models based on the equations of motion show limitations in predicting future states of geomorphologic systems [Werner, 1999]. It is important to analyze the intrinsic predictability of attributes of these systems, such as flow, sediment flux, channel geometry and shifts, and to understand how system predictability varies as a function of scale, adapting techniques from other fields [Basu et al., 2002]. Theoretical advances in the physics and dynamics of coupled systems have considerably advanced over the past few years but much remains to be done to apply these advances to the highly nonlinear, highly interactive space-time evolution of Earth surface systems.

\subsubsection{Self Organization, Pattern Formation, and Moving Boundaries}

[23] Channels and channel networks represent the most spatially significant instance of spontaneous pattern formation and self-organization on Earth. In many cases the evolution of these patterns requires tracking evolving boundaries between specific transport domains, for instance, the boundary between gravel-dominated and sand-dominated 
sediment transport, a shoreline, or an ecological boundary. These are termed "moving boundary" problems because the front must be found and tracked as part of the problem's solution [Paola and Voller, 2005; Swenson et al., 2000; Voller et al., 2006]. The development of numerical techniques for tracking moving boundaries, starting with methods developed for, for instance, solid-liquid fronts, is a major research frontier in surface dynamics.

\subsection{Role of New Observational Techniques}

[24] Geosciences is witnessing an era of rapid development of new sensor technology and observational techniques that are poised to revolutionize our understanding, and thus predictive modeling capabilities, of Earth surface dynamics. High-resolution topography (e.g., $1 \mathrm{~m}$ topography data from LIDAR) and wireless sensor technology with embedded networked sampling (e.g., concurrent and adaptive sampling over large spatial coverage and short time intervals; and particle-tracking techniques) provide an opportunity to bridge the gap between the small scales at which biogeochemical processes occur and the larger scales at which organizing patterns are observed. Wireless technology, smart sensors with controlled activation capabilities, e.g., during extreme floods or high temperatures, small sensors that can be attached to moving gravel ("talking stones") [McNamara and Borden, 2004], isotopes for dating, radar imaging, etc. can all work synergistically to sample processes at scales ranging from a few $\mathrm{mm}$ and seconds to planetary length and time scales. However, despite the extreme spatial and temporal variability and the large range of scales of interacting processes, one cannot sample everywhere and all the time. Thus the challenge exists to use even rudimentary knowledge of the underlying variability, of cause-effect relationships, and of possible scaling relationships to optimize sampling network design. To that effect, detailed knowledge of topography is expected to play a significant role.

[25] The newly available high-resolution LIDAR topographic data [Carter et al., 2001] provide the opportunity to explicitly resolve channel and floodplain morphology, stream corridor geometry (including geomorphologic disturbances at confluences), and vegetation characteristics throughout the basin. Having such high-resolution channel morphology continuously available along stream reaches and over the whole watershed offers the potential of understanding cause-effect relationship between channel attributes and biological and geochemical processes. Such relationships can guide efficient design of environmental observatories and also guide efforts to upscale local processes, e.g., algal production [Hondzo and Wang, 2002], denitrification potential, etc., to stream reach averages, and ultimately to indices characterizing the state of the whole watershed [Boyer et al., 2006]. However, existing methods for extracting channel networks from $90 \mathrm{~m}$ or $30 \mathrm{~m}$ DEMs do not perform well when applied to the extraction of topographic features from $1 \mathrm{~m}$ LIDAR data. New "geomorphologically informed" image processing techniques are needed to take advantage of the rich information provided by these sensors, including the automatic mapping of service roads and skid trails created during logging that are large contributors of sediment to the streams.

\subsection{Role of Laboratory Studies}

[26] The complexity and tendency toward spontaneous pattern formation of channels and channel networks make them inviting targets for study under controlled conditions in a laboratory setting (flume or outdoors facility) where individual and interactive effects of primary drivers can be teased apart. Experiments yield improved process understanding and provide the basis for testing hypotheses rigorously. Laboratory study is a useful complement to field studies for processes that are too slow, infrequent, inaccessible, and/or violent to permit direct observation in the field. This includes a wide range of important natural processes, so we expect experimentation to play a major role in Earth surface science for some time to come. Laboratory study has been especially fruitful for the study of self-organization, where the ability of the experimental system to develop patterns on its own is important. Self organized natural patterns that are fractal (a small part of the spatial pattern shows statistical similarity to the whole pattern) are especially appropriate for laboratory study even where formal conditions for dynamic similitude cannot be satisfied. A newer area for experimental study is physical-biological interactions, for example the contest between vegetation and physical processes that strongly influences the form and kinematics of river channels [Gran and Paola, 2001; Tal et al., 2004]. In addition, we see bright prospects for experiments combining physical, geochemical and microbial processes, but as far as we know very little work has been done in this area.

\section{Conclusion}

[27] Prediction of the evolution of the Earth's surface is at the heart of environmental science: the surface is the environment in which most life and human activity take place. At present, we do not have the tools needed to reliably model and predict the interwoven physical, biological, geochemical, and human dynamics that shape the Earth's surface. Developing these tools will require integrating a broad range of fields including Earth sciences, hydrology, ecology, geochemistry, social sciences, physics, and mathematics. Earth surface dynamics should be an attractive area for young researchers with quantitative skills and a taste for interdisciplinary work.

[28] Acknowledgments. The authors acknowledge the input of many colleagues over the past 3 years in shaping the research agenda of the National Center for Earth-surface Dynamics (NCED), an NSF Science and Technology Center headquartered at St Anthony Falls Laboratory. University of Minnesota. NCED is funded by NSF's Office of Integrative Activities (OIA) under agreement EAR-0120914.

\section{References}

Abreu, V., M. Sullivan, C. Pirmez, and D. Mohrig (2003), Lateral accretion packages (LAPs): An important reservoir element in deep water sinuous channels, Mar. Pet. Geol., 20, 631-648.

Basu, S., E. Foufoula-Georgiou, and F. Porte-Agel (2002), Predictibility of atmospheric boundary-layer flows as a function of scale, Geophys. Res. Lett., 29(21), 2038, doi:10.1029/2002GL015497.

Bennett, S. J., and A. Simon (Eds.) (2004), Riparian Vegetation and Fluvial Geomorphology, Water Sci. Appl. Ser., vol. 8, 290 pp., AGU, Washington, D. C.

Bernhardt, E. S., et al. (2005), Synthesizing U.S. river restoration efforts, Science, 308, 636-637.

Bonan, G. B., K. W. Oleson, M. Vertenstein, S. Levis, X. Zeng, Y. Dai, R. E. Dickinson, and Z.-L. Yang (2002), The land surface climatology of the 
Community Land Model coupled to the NCAR Community Climate Model, J. Clim., 15, 3123-3149.

Boyer, E. W., R. W. Howarth, J. N. Galloway, F. J. Dentener, P. A. Green, and C. J. Vörösmarty (2006), Riverine nitrogen export from the continents to the coasts, Global Biogeochem. Cycles, GB1S91, doi:10.1029/ 2005GB002537.

Carter, W., R. Shrestha, G. Tuell, D. Bloomquist, and M. Sartori (2001), Airborne laser swath mapping shines new light on Earth's topography, Eos Trans. $A G U, 82,549-550,555$.

Caylor, K. K., T. M. Scanlon, and I. Rodriguez-Iturbe (2004), Feasible optimality of vegetation patterns in river basins, Geophys. Res. Lett., 31, L13502, doi:10.1029/2004GL020260.

Caylor, K. K., S. Manfreda, and I. Rodriguez-Iturbe (2005), On the coupled geomorphological and ecohydrological organization of river basins, $A d v$. Water Resour., 28, 69-86.

Das, H. S., J. Imran, C. Pirmez, and D. Mohrig (2004), Numerical modeling of flow and bed evolution in meandering submarine channels, J. Geophys. Res., 109, C10009, doi:10.1029/2002JC001518.

Davies, R. J., and H. W. Posamentier (2005), Geologic processes in sedimentary basins inferred from three-dimensional seismic imaging, GSA Today, 15, 4-9.

Dietrich, E. W., and W. T. Perron (2006), The search for a topographic signature of life, Nature, 439, 411-418.

Dietrich, W. E., D. Bellugi, A. M. Heimsath, J. J. Roering, L. Sklar, and J. D. Stock (2003), Geomorphic transport laws for predicting landscape form and dynamics, in Prediction in Geomorphology, Geophys. Monogr. Ser., vol. 135, edited by P. Wilcock and R. Iverson, pp. 103-132, AGU, Washington, D. C.

Dodov, B., and E. Foufoula-Georgiou (2004), Generalized hydraulic geometry: Insights based on fluvial instability analysis and a physical model, Water Resour. Res., 40, W12201, doi:10.1029/2004WR003196.

Dodov, B., and E. Foufoula-Georgiou (2005), Fluvial processes and streamflow variability: Interplay in the scale frequency continuum and implications for scaling, Water Resour. Res., 41, W05005, doi:10.1029/ 2004WR003408.

Federici, B., and G. Seminara (2003), On the convective nature of bar instability, J. Fluid Mech., 487, 125-145.

Foufoula-Georgiou, E., and V. B. Sapozhnikov (2001), Scale invariances in the morphology and evolution of braided rivers, Math. Geol., 33, 273-291.

Gran, K., and C. Paola (2001), Riparian vegetation controls on braided stream dynamics, Water Resour. Res., 37, 3275-3283.

Green, E. G., W. E. Dietrich, and J. F. Banfield (2006), Quantification of chemical weathering rates across an actively eroding hillslope, Earth Planet. Sci. Lett., in press.

Gupta, V. K., O. J. Mesa, and D. Dawdy (1994), Multiscaling theory of flood peaks: Regional quantile analysis, Water Resour. Res., 30, $3405-$ 3421

Hondzo, M., and H. Wang (2002), Effects of turbulence on growth and metabolism of periphyton in a laboratory flume, Water Resour. Res., 38(12), 1277, doi:10.1029/2002WR001409.

Imran, J., G. Parker, and C. Pirmez (1999), A nonlinear model of flow in meandering submarine and subaerial channels, J. Fluid Mech., 400, $295-331$.

Intergovernmental Panel on Climate Change (2001), Climate Change 2001: Synthesis Report, edited by R. T. Watson and the Core Writing Team, 184 pp., Cambridge Univ. Press, New York.

Lunt, I. A., J. S. Bridge, and R. S. Tye (2004a), Development of a 3-D depositional model of braided river gravels and sands to improve aquifer characterization, in Aquifer Characterization, edited by J. S. Bridge and D. Hyndman, pp. 139-169, Soc. for Sediment. Geol., Tulsa, Okla.

Lunt, I. A., J. S. Bridge, and R. S. Tye (2004b), A quantitative, threedimensional depositional model of gravelly braided rivers, Sedimentology, 51, 377-414.

McNamara, J. P., and C. Borden (2004), Observations on the movement of coarse gravel using implanted motion-sensing radio transmitters, Hydrol. Processes, 18, 1871-1884.

Menadbe, M., and M. Sivapalan (2001), Linking space-time variability of rainfall and runoff fields on a river networks: A dynamic approach, $A d v$. Water Resour., 24, 1001-1014.

Mitchell, N. C. (2004), Form of submarine erosion from confluences in Atlantic USA continental slope canyons, Am. J. Sci., 304, 590-611.

Murray, A. B., and C. Paola (1994), A cellular model of braided rivers, Nature, 371, 54-57.

Paola, C., and V. R. Voller (2005), A generalized Exner equation for sediment mass balance, J. Geophys. Res., 110, F04014, doi:10.1029/ 2004JF000274.
Parker, G., and N. Izumi (2000), Purely erosional cyclic and solitary steps created by flow over a cohesive bed, J. Fluid Mech., 419, 203-238.

Porporato, A., and I. Rodriguez-Iturbe (2002), Ecohydrology: A challenging multidisciplinary research perspective, J. Hydrol. Sci., 47, 811821 .

Porporato, A., E. Daly, and I. Rodriguez-Iturbe (2004), Soil water balance and ecosystem response to climate change, Am. Nat., 164, 625-632.

Power, M. E., A. Sun, G. Parker, W. E. Dietrich, and J. T. Wootton (1995), Hydraulic food-chain models, BioScience, 45, 159-167.

Power, M. E., N. Brozovic, C. Bode, and D. Zilberman (2005), Spatially explicit tools for understanding and sustaining inland water ecosystems, Frontiers Ecol. Environ., 3, 47-55.

Rodriguez-Iturbe, I., and A. Rinaldo (1997), Fractal River Basins, 539 pp., Cambridge Univ. Press, New York.

Sambrook Smith, G., J. Best, C. Bristow, and G. Petts (Eds.) (2006), Braided Rivers, 368 pp., Blackwell, Malden Mass.

Sapozhnikov, V. B., and E. Foufoula-Georgiou (1997), Experimental evidence of dynamic scaling and indications of self-organized criticality in braided rivers, Water Res. Res., 33, 1983-1991.

Seminara, G., and M. Tubino (1989), Alternate bars and meandering: Free, forced and mixed interactions, in River Meandering, Water Resour. Monogr. Ser., vol. 12, edited by S. Ikeda and G. Parker, pp. 267-320, AGU, Washington, D. C.

Seminara, G., and M. Tubino (2001), Sand bars in tidal channels. Part 1. Free bars, J. Fluid Mech., 440, 49-74.

Stainforth, D. A., et al. (2005), Uncertainty in predictions of the climate response to rising levels of greenhouse gases, Nature, 433, 403-406.

Sun, T., and G. Parker (2005), Transportational cyclic steps created by flow over an erodible bed. Part 2. Theory and numerical simulation, $\mathrm{J}$. $\mathrm{Hy}$ draul. Eng., 43, 502-514.

Sun, T., P. Meakin, T. Jøssang, and P. Meakin (1996), A simulation model for meandering rivers, Water Resour. Res., 32, 2937-2954.

Sun, T., C. Paola, G. Parker, and P. Meakin (2002), Fluvial fan deltas: Linking channel processes with large-scale morphodynamics, Water Resour. Res., 38(8), 1151, doi:10.1029/2001WR000284.

Swenson, J. B., V. R. Voller, C. Paola, G. Parker, and J. G. Marr (2000), Fluvio-deltaic sedimentation: A generalized Stefan problem, Eur. J. Appl. Math., 11, 433-452.

Syvitski, J. P. M. (2005), The morphodynamics of deltas and their distributary channels, in River, Coastal, and Estuarine Morphodynamics, pp. 143-150, Springer, New York.

Tal, M., K. Gran, A. B. Murray, C. Paola, and D. M. Hicks (2004), Riparian vegetation as a primary control on channel characteristics in multi-thread rivers, in Riparian Vegetation and Fluvial Geomorphology, Water Sci. Appl. Ser., vol. 8, edited by S. J. Bennett and A. Simon, pp. 43-58, AGU, Washington, D. C.

Voller, V. R., J. B. Swenson, W. Kim, and C. Paola (2006), A fixed grid method for moving boundary problems on the Earth's surface, Int. J. Heat Fluid Flow, in press.

Werner, B. T. (1999), Complexity in natural landform patterns, Science, 284, $102-104$.

Wilcock, P. R. (1997), Friction between science and practice: The case of river restoration, Eos Trans. $A G U, 78,454$.

Wohl, E., P. L. Angermeier, B. Bledsoe, G. M. Kondolf, L. MacDonnell, D. M. Merritt, M. A. Palmer, N. L. Poff, and D. Tarboton (2005), River restoration, Water Resour. Res., 41, W10301, doi:10.1029/ 2005WR003985.

W. E. Dietrich, Department of Earth and Planetary Science, University of California, Berkeley, CA 94720, USA

E. Foufoula-Georgiou, M. Hondzo, C. Paola, and V. Voller, St. Anthony Falls Laboratory, University of Minnesota Twin Cities, Minneapolis, 2 Third Avenue SE, MN 55414, USA. (cpaola@umn.edu)

D. Mohrig, Department of Earth, Atmospheric, and Planetary Science, Massachusetts Institute of Technology, Cambridge, MA 02139, USA.

G. Parker, Department of Civil Engineering, University of Illinois, Urbana, IL 61801, USA.

M. E. Power, Department of Integrative Biology, University of California, Berkeley, CA 94720, USA.

I. Rodriguez-Iturbe, Department of Civil and Environmental Engineering, Princeton University, Princeton, NJ 08544, USA.

P. Wilcock, Department of Geography and Environmental Engineering, Johns Hopkins University, Baltimore, MD 21218, USA. 